\title{
Dobutamine stress cardiovascular MR in clinical practice: a single centre experience
}

\author{
SK Khambekar ${ }^{*}$, M Byrant, JS Shambrook, CP Peebles, IW Brown, SP Harden \\ From 2011 SCMR/Euro CMR Joint Scientific Sessions \\ Nice, France. 3-6 February 2011
}

\section{Introduction}

Dobutamine stress cardiovascular magnetic resonance (DCMR) is a robust tool for determining the presence of inducible ischaemia in patients with known or suspected coronary artery disease (CAD).

\section{Purpose}

To assess the safety of DCMR in clinical practice in a tertiary referral centre in the UK.

\section{Methods}

We retrospectively studied all DCMR scans performed between May 2006 and March 2009.

\section{CMR Protocol}

CMR studies were performed using a $1.5 \mathrm{~T}$ (Siemens Avanto) clinical CMR scanner. After a full functional assessment using steady state free precession (SSFP) cine imaging, three short axis images together with the three long axis (2-, 3- and 4- chamber) images were selected and these were then acquired at each dose increment during a standard dobutamine-atropine protocol. Dobutamine was infused in $10 \mathrm{mcg} / \mathrm{kg} / \mathrm{min}$ increments up to a maximum of $40 \mathrm{mcg} / \mathrm{kg} / \mathrm{min}$. Initial $5 \mathrm{mcg} / \mathrm{kg} / \mathrm{min}$ increments were used where there was a wall motion abnormality at rest. The protocol was continued until target heart rate was achieved or until there was a recognised indication to stop prior to reaching target heart rate. Side effects and complications were recorded.

\section{Results}

Out of 455 patients, 21(4.6\%) patients were unable to undergo the procedure (claustrophobia, MR incompatible device in situ)
434 scans were performed in patients with a mean age of 64 years (range 13-86). 419 patients had a full dose study to assess for inducible ischaemia while 15 patients had a low dose protocol to determine myocardial viability.

The average dose of dobutamine required for each full dose study was $24 \pm 9$ micrograms $/ \mathrm{kg} / \mathrm{min}$ with additional atropine used in $119(27.4 \%)$ patients. Target heart rate was achieved in 334 (79\%) patients.

Of the 85 patients who failed to achieve target heart rate, 37(43\%) developed significant chest pain, requiring the infusion to be stopped. Chest pain was the commonest cardiac side effect but in only $20 \%$ of these patients was the scan stopped early. 5 patients needed in-patient overnight observation for hypotension (2), broad complex tachycardia (1) and fast AF (2). None of these had a significant rise in troponin.

Minor non-cardiac side effects occurred in 18 (4\%) patients (eg nausea).

\section{Conclusions}

Our experience suggests DCMR is a safe and feasible technique in routine clinical practice for assessing patients with suspected or known CAD and has a low complication rate.

Published: 2 February 2011

doi:10.1186/1532-429X-13-S1-P227

Cite this article as: Khambekar et al:: Dobutamine stress cardiovascular

MR in clinical practice: a single centre experience. Journal of

Cardiovascular Magnetic Resonance 2011 13(Suppl 1):P227.

Southampton University Hospital NHS Trust, Southampton, UK 